\title{
Development of operating conditions of district heating systems with quality regulation
}

\author{
Vyacheslav V. Tokarev ${ }^{1, *}$, and Zoya I. Shalaginova ${ }^{1}$ \\ ${ }^{1}$ Melentiev Energy Systems Institute of Siberian Branch of the Russian Academy of Sciences (ESI SB \\ RAS), 130 Lermontov Str., Irkutsk 664033, Russia
}

\begin{abstract}
District heating systems (DHS) have developed as large-scale and very complex engineering structures. In different countries of the world, are used various strategies of their regulation: by quality, by quantity, by combining of quality and quantity. The purpose of the operating conditions development is to find such conditions under which the supply of consumers with the required amount of heat by given quality while observing all the technical and technological requirements. The task of calculating the DHS conditions is to find the distribution of flows, pressures and temperatures across all elements of the design scheme for a given topology, hydraulic and thermal characteristics of its elements and boundary conditions. There are two types of calculation of DHS conditions: adjustment and verification. In article presented DHS operating regime development technology. The "Angara-HN" software can perform the whole complex of calculations.
\end{abstract}

\section{Introduction}

The directions of development of heat supply to consumers are: achieving a high level of comfort in the rooms, including an increase in the quality of heat supply at its affordable cost; reduction of heat losses during its transportation and consumption; ensuring the safety, reliability, efficiency of heat supply with a high level of observability and controllability of a complex of systems for generating, transporting and using heat. Russian DHS are very large-scale and complex engineering structures. As a rule, they have a heterogeneous hierarchical variable in time structure, a multi-loop network scheme widely spaced on territory, variable parameters and regimes of operation of its elements, the presence of many other properties suggesting the need to consider them as large and complex physical and technical systems.

Globally, the level of centralization of DHS is growing. DHS are being built and actively developed in Europe and the CIS, China, Mongolia, etc. [1-3]. In Denmark [4], Sweden [5], Finland [6], Estonia, Latvia, Iceland, Lithuania, Poland [7], Russia [8-10] and northern China, the level of heat supply centralization exceeds 50\% [11]. Moreover, over the past decade alone, the level of centralization of heat supply in northern China has increased several times. Prerequisites for the development of DHS exist in the USA [12]

* Corresponding author: tslava@isem.irk.ru 
and Canada. However, few floor construction of USA settlements along with a relatively short and warm winter period do not require much heat for heating. Historically, in the USA, well develop centralized water, gas and electricity supply systems. As for heating and hot water supply, the systems are decentralized. Cold water heating are performing directly at consumer buildings using gas or electric boilers.

\section{Ways to regulate heat supply in Russia and abroad}

The control of heat supply regimes in DHS of Russia and in several foreign countries is fundamentally different. If in former USSR countries historically they were widely developed quality regulation DHS (management by changing of the heat source (HS) temperature outlet depending on the outdoor air temperature), in European countries systems were created for quantity regulation of heat consumption directly at consumer heating stations. When quality control, the flows rates in the network varies slightly over a long period of time (time of year), which allows us to simplify the control structure and cost of consumer heating stations. However, rough errors in the forecast of the outdoor temperature lead to significant deviations of the internal air parameters of consumers from the norm. Quantity regulation at consumers allows them to respond flexibly to their needs, sometimes completely blocking heat consumption during the daytime or severely limiting it during the night period. Such regulation requires a multitude of sensors and automatic controllers interconnected each other in a complex system, making the heating system by a separate consumer building expensive but providing better controllability and observability. The temperature of water at the HS outlet is keeping as constant and volumetric storage tanks are using to smooth out consumption irregularities. When quality regulation, suppliers of thermal energy tend to increase the range of temperature regulation, heating the water at the source outlet in the maximum cold week period to $130{ }^{\circ} \mathrm{C}$ or $150{ }^{\circ} \mathrm{C}$, and sometimes higher. This allows suppliers to reduce capital investment in the pipeline network by reducing the diameters of the pipeline, reducing the metal consumption and by lower require power of electricity for pumping water. In quantity regulation, when part of the time of day water in the system moves at a very low speed, suppliers tend to reduce the HS outlet water temperature and increase the insulation of the pipes in order to reduce as much as possible the heat loss from the pipeline network to the environment $[13,14]$.

In recent years, both in Russia and abroad, there has been a smooth transition to combine quality and quantity regulation. In Russia, complex automation of consumer heating stations is under way during new construction and the consumer heating stations of existing buildings are partially reconstructing. In Europe, by increasing the temperature water at HS outlet during peak consumption hours, it is proposing to solve the problem of the heating networks $(\mathrm{HN})$ ability to miss the required water flow [15]. In China, systems with intermediate levels of regulation are often using to heat megacities. From HS that are tens of kilometers away from the city, heat is transported to thermal stations (TS), while regulating the temperature at the HS according to a quality regulation scheme. Then, at TS, the temperature is lowering and in the secondary circuit from the TS to the consumers, heat is delivered according to a quantity control scheme, controlling the required flow rate of the heat carrier directly at the consumers.

The type of regulation determines the DHS operation conditions and methods of their organization. In the Russian DHS, the main adjustment of HNs is required at least once a year, during the inter-heating period. During this work are updating the required parameters of throttling (narrowing) devices which installed or will be installed on the pipelines and at consumers. The entire system is reconfiguring. With the help of these throttling devices, a constant hydraulic regime is maintaining for the next heating period. For a European, fully automated, quantity controlled DHS, it may seem that this type of adjustment is not 
relevant, since automation controls the flow distribution in the network. However, from the point of view of the all DHS functioning, the control range for consumers must be limited from above, it will not allow of consumers (who are closer to the source) to "drag" the flow of the heat carrier on themselves in the shortage period of heat energy, thereby driving remote consumers into even more complex operating conditions. At the same time, it is necessary to limit the flow rate of the heat carrier from below, preventing the circulation in $\mathrm{HN}$ from completely stopping, since the absence of circulation can lead to pipeline freezing in the case of low outdoor air temperatures.

\section{Aims and tasks of the organization of DHS regimes in Russia}

The aim of the development of operating regimes is to find such conditions under which is ensuring the supply of consumers with the required amount of heat of a given quality while observing all the technical and technological requirements. The conditions are understood as the parameters of the heat carrier at the HS, TS and pumping stations, as well as the composition and parameters of throttling devices on the network and at consumers.

The task of calculating the DHS regimes is to find the distribution of heat carrier flows, pressures and temperatures across all elements of the design scheme for a given topology, hydraulic and thermal characteristics of its elements and boundary conditions. The boundary conditions are understood to be that part of the regime parameters, which must be fixed in order for the rest to be determined unambiguously from the equations of the model of the thermal-hydraulic regime. In the role of such conditions, as a rule, are setting the loads of consumers, the pressure in the sites of feed, the temperature of supply and feed water at HS. When organizing the operating DHS regimes for the next heating season, the regimes are calculated taking into account the thermal loads introduced in the coming period, new equipment and capacities.

There are two types of calculation of DHS conditions: adjustment and verification. The adjustment calculation is associated with the determination of conditions that ensure compliance with all technical and technological requirements for a given consumer loads. The aim of the verification calculation is to identify the degree of compliance with all requirements for the regime, including the level and quality of supply to consumers, given the boundary conditions and characteristics of all elements, including consumption systems.

Among the many requirements imposed on the operation regimes DHS, three main groups are traditionally distinguished: 1) requirements arising from the functional purpose DHS, providing all consumers with the necessary heat; 2) economic, associated with minimizing the cost of transporting the heat carrier to consumers; 3) technological, determined by the permissible operating conditions of the equipment.

Practically for all existing DHS, the concept of program management is applied, according to which at the upper level of the temporal hierarchy the tasks of planning regimes for a given lead time are solved, and at the lower level (operational management) they are correcting (or are stabilizing) to ensure the planned regimes against the background of random perturbations [16-17].

Traditionally, the tasks of planning normal and post-emergency regimes of DHS in Russia are solving by means of multivariate calculations of flow distribution. At the same time, the process of analyzing and selecting regimes is entirely entrusting to the engineer, and the quality of the decisions made directly depends on his experience and qualifications, as well as on the scale and complexity of DHS itself. At the same time, the exit of regime parameters beyond technologically permissible limits may lead to destruction or increased wear of equipment, disruption of the level of consumer supply and other negative consequences. In practice, the tasks of planning normal and post-emergency regimes of DHS are solved occasionally, which is due to the large amount of work on: preparing and 
refining information about the schemes and parameters of the DHS; carrying out multivariate calculations of high complexity; solving nontrivial problems of analysis and comparison of variants. Since the results of the development of operational regimes become obsolete quickly, this periodicity leads to a decrease in the energy efficiency of DHS in normal, and even more so in emergencies. This determines the relevance of automating decision-making processes when planning regimes based on new information technologies and mathematical modeling.

\section{Methodical background}

The Laboratory of Pipeline and Hydraulic Systems of ESI SB RAS for a number of years conducts theoretical and applied research in the field of mathematical modeling of DHS in the framework of the scientific direction formulated and developed here - the theory of hydraulic circuits [18]. The subject of this theory is the general methods of calculation and optimization of pipeline systems of complex multi-loop structure. Currently, based on these methods, a developed system of mathematical models and methods has been created for calculating and analyzing the hydraulic and thermal-hydraulic regimes of DHS [19-28]. An information and computing complex (ICC) "ANGARA-HN" software has been created for calculating and analyzing the operation conditions of DHS during their planning [23,2931]. The integration of model, methodical and software with information technologies provides the possibility of full-scale disclosure of the potential of the theory of hydraulic circuits for research, analysis and organization of the operating regimes of large DHS and other pipeline systems [32].

ICC "ANGARA-HN" is provides the ability to create graphical, hierarchically related databases (DB) for DHS, including electronic maps and site plans, graphic representations of schemes of heat networks and network facilities, digital and textual information on the parameters of elements of DHS. In addition, ICC allows solving both analytical and informational tasks within a single user interface in the Windows OS.

\section{DHS operating regimes development technology}

The development of regimes with the help of ICC "ANGARA-HN" requires the creation of a computer model of DHS, including design schemes for main and distribution heat networks, information about the types and parameters of its elements, restrictions on regime parameters. To find the coefficients of equivalent roughness and specific heat losses coefficient of pipelines, it is advisable to use the results of tests of heat networks for hydraulic and heat losses $[33,34]$.

DHS operating regimes development technology includes the following steps: 1) the analysis of the existing state of the DHS and regimes under the prevailing operating conditions is carrying out, the purpose of which is to identify "bottlenecks", violations of the regime and quantify the existing level of supply to consumers. For this aim, calculations are performing on the reproduction of thermal-hydraulic regimes of DHS with the existing schedule of their operation and parameters on HS and TS, in which DHS worked past heating season. In some cases, to ensure the adequacy of the model, it is calibrating according to the measurement data of the regime parameters (pressures, flow rates, temperatures). In [35] given requirements and recommendations for permissible values of the parameters of the mode of the various elements of the DHS; 2) according to the results of the analysis of the regime, the dictating elements of the system (nodes, consumers, pipelines) with violations of the permissible values of their parameters (pressure, temperature, velocity, head difference between supply and return pipeline, etc.) are 
determined when the existing DHS operation schedule; 3) DHS rational allowable regime of operating is developing.

Among all the requirements for the regime, it is possible to distinguish those whose satisfaction in most cases will ensure the admissibility of the regime as a whole. The head in the pipeline at all points of the network must be greater than $5 \mathrm{~m}$. The head in the return pipeline of the consumer internal systems should be higher than the height of the building plus $5 \mathrm{~m}$. The difference between supply and return pipeline head at the inlet at the consumer must be not less than that required by the technological conditions of consumer's heating station operation. The pressure in the supply pipe at all points of the network must be lower than the equipment required because of strength. The temperature of the internal air at the consumer must be within the specified range. When the temperature graph is above $95 / 70$, it is necessary to ensure the non-boiling pressure of the heat carrier in all points of the supply pipeline. In the presence of pumping equipment in front of the pumps, it is necessary to provide a pressure higher than the required one, taking into account the cavitation margin. For each of these restrictions, a dictating element is determined, the fulfillment of the conditions for which ensures the fulfillment of these parameters throughout the network.

The heat network may have controls (TS, pumping stations, regulators, valves, etc.). Each of them divides the DHS into zones. To determine the rational parameters of the control of the DHS regime for each of the zones, it is necessary to define its own set of dictating elements, which will uniquely determine the required parameters of the HS regime (pressure, temperature) and at the beginning of each zone (pressure). Based on these parameters, it is possible to calculate the resistance of the throttling devices (the required holes diameters of nozzles devices at consumers) or the settings of the regulators and balancing valves. The sequence of determining the operating parameters of the operating regime on the real example of Cheremkhovo (Russia) is describing in [36].

If it is impossible to determine the parameters for the organization of the allowable condition, pipeline sections for reconstruction are finding from the condition for exceeding the specific pressure loss. With the presence of circuits in the network, it is possible to achieve an increase in its flow throughput by changing partitioning of DHS scheme [37]. Because of the calculations, a set of measures is planning to ensure compliance with all requirements, including the level of heat supply to consumers [38].

\section{Conclusion}

Based on the analysis of the current state of DHS and the current practice of technological management of their operation in Russia and abroad, a required scientific and methodological basis has defined for automating the development of the DHS operational regimes. A comparative analysis of the methods of control of DHS regimes in Russia and abroad is given. The aims and tasks of calculating the DHS operating regimes were determined with by help of the ICC "Angara-HN", which provides support for computerbased DHS models and automates the processes of calculating the regimes and analyzing their results. The content of the multi-stage technology for the development of technologically rational DHS operational regimes, satisfying all technical limitations, is disclosed.

The research was carried out within the project III.17.4.3 of the Fundamental research program of SB RAS (AAAA-A17-117030310437-4) with finance support of RFBR and the Government of Irkutsk Region in the framework of research project № 17-48-380021 


\section{References}

1. A. Colmenar-Santo et al., Renewable and Sustainable Energy Reviews, 62, 621 (2016)

2. B. Rismanchi, Renewable and Sustainable Energy Reviews, 75, 571 (2017)

3. T.A. Rafalskaya et al, Proceedings of the NSU of A and CE, 21, 1, 138 (2018)

4. M. Münster et al., Energy, 48, 1, 47 (2012)

5. S. Werner Energy, 126, 419 (2017)

6. S. Paiho, F. Reda, Energy Reviews, 65, 915 (2016)

7. K. Wojdyga, M. Chorzelski, Energy Procedia, 116, 106 (2017)

8. I.A. Bashmakov, Energosberezhenie, 2, 46 (2010)

9. I.A. Bashmakov, Center for the efficient use of energy, http://www.cenef.ru/file/Heat.pdf

10. I.A. Bashmakov, Novosti Teplosnabzheniya, 2-4, (2008)

11. S. Werner, Energy, 137, 617 (2017)

12. H.C. Gils, Energy, 58, 318 (2013)

13. H. Lund, S. Werner, R. Wiltshire, S. Svendsen et al., Energy, 68, 1 (2014)

14. D. Schmidt, et al., Energy Procedia, 116, 26 (2017)

15. K. Lichtenegger, et al., Sustainable Energy, Grids and Networks, 11, 1 (2017)

16. N.N. Novitsky et al., Energy of Russia in the XXI century, 447 (Irkutsk: ESI, 2001)

17. N.N. Novitsky et al., Pipeline systems in energy sector, (Novosibirsk: Nauka, 2017)

18. A.P. Merenkov, V.Ya. Khasilev, Theory of hydraulic circuits. (Moscow:Nauka,1985)

19. N.N. Novitsky, Z.I. Shalaginova, et al., Izvestiya RAS: Energetika. 1, 12 (2018)

20. A.V. Alekseev et al., Investigations and developments of SB RAS in the area of energy efficient technologies, 38 (Novosubirsk: Institute of Thermal Physics, 2009)

21. Z.I. Shalaginova, Thermal Engineering. 56, 12, 1016 (2009)

22. N.N. Novitsky et al., Pipeline systems in energy sector (Novosibirsk: Nauka, 2014)

23. N.N. Novitsky et al., Pipeline systems in energy sector (Novosibirsk: Nauka, 2015)

24. Z.I. Shalaginova, Thermal Engineering, 63, 3, 222 (2016)

25. Z.I Shalaginova, Thermal Engineering, 51. 7, 554 (2004)

26. Z.I. Shalaginova, Thermal Engineering. 63, 3, 222 (2016)

27. Z.I. Shalaginova, V.V. Tokarev, E3S Web of Conferences, 39, 01003 (2018)

28. Z.I. Shalaginova, V.V. Tokarev, E3S Web of Conferences, 39, 03007 (2018)

29. N.N. Novitsky et al., Proceedings of IrSTU, 11, 126 (2018)

30. N.N. Novitsky et al., Proc. of Univ. Invest. Construction. Real estate, 8, 4, 139 (2018)

31. N.N. ,Novitsky, et al., Energy, DOI: 10.1016/j.energy.2018.02.070 (2018)

32. V.V. Tokarev, Z.I. Shalaginova, Proceedings of IrSTU, 12, 240 (2011)

33. N.N. Novitsky, O.A. Grebneva et al., Thermal Engineering, 65, 7, 453 (2018)

34. O.A. Grebneva, N.N. Novitsky, Thermal Engineering, 61, 10, 754 (2014)

35. V.V. Tokarev, Z.I. Shalaginova, Thermal Engineering, 63, 1, 68 (2016)

36. Z.I. Shalaginova, V.V. Tokarev, Thermal Engineering, 66, 10 (2019)

37. V.V. Tokarev, Thermal Engineering, 65, 6, 400 (2018)

38. Z.I. Shalaginova, Thermal Engineering, 61, 11, 829 (2014) 